\title{
COMMISSION 30: RADIAL VELOCITIES (VITESSES RADIALES)
}

\author{
Report of Meetings, 21 and 23 August 1973
}

ACting PResident: A. H. Batten.

Secretary: A. G. Davis Philip.

(1) No objections were raised to the printed report of the Commission. A formal motion that the list of 21 faint stars listed in the report be adopted as new standard-velocity stars was carried unanimously. The thanks of the Commission were expressed to Drs Heard and Fehrenbach for their work on these new standards. Thanks were also expressed to Dr D. S. Evans and Drs. Abt and Biggs for their work on catalogues and bibliographies of radial velocities, respectively.

(2) The three resolutions in the name of the Commission on the General Assembly agenda (items $11 \mathrm{~g}$ (i)-(iii)) were discussed. After discussions between the Acting President and the Secretary of Commission 40 the two Commissions agreed to set up a joint working group to study (i) and (ii) to report back to them at the XVI General Assembly. Meanwhile these two resolutions were to be withdrawn from the agenda of the General Assembly. The Commission appointed Batten (Chairman), Fehrenbach, and de Vaucouleurs as its representatives on the working group. The resolution (iii) was affirmed by the Commission. In addition, the Commission unanimously welcomed the proposal of Commission 42 to enlarge its scope to include spectroscopic binaries.

(3) After discussion the following officers and Organizing Committee were adopted, subject to approval by the General Assembly and Executive Committee, as appropriate.

President: R. F. Griffin, Vice-President: A. H. Batten, Organizing Committee: R. Bouigue, Mme M. Duflot, H. Gollnow, J. F. Heard, L. Oetken, A. G. Davis Philip, Mrs V. C. Rubin.

Four new members were elected: Y Georgelin, A. Pedoussaut, K. Serkowski, and R. V. Willstrop. The Commission reaffirmed its desire to include radio astronomers in its membership.

(4) The question of working rules for the Commission was referred to the incoming Organizing Committee. The Commission stressed that IAU Reports were very useful, and should continue to be published in substantially their present form. The determination of priorities in the field of radial velocities was delegated to a committee consisting of Batten, Fehrenbach, and de Vaucouleurs. They reported as follows to the General Secretary.

Radial velocities are fundamental data essential to studies of:

(i) galactic structure and dynamics,

(ii) stellar masses,

(iii) structure of stellar atmospheres (including those of Cepheid variables),

(iv) velocity dispersions in star clusters, galaxies, and clusters of galaxies,

(v) anomalous red shifts in the spectra of stars (e.g. $W-R$ stars) and of galaxies. (Are the red shifts Doppler effects?).

Therefore the Commission urges the importance of obtaining large numbers of radial velocities of the accuracy required for the resolution of these problems. It considers the provision of adequate t $t$ lescope time and modern instrumentation for the measurement of radial velocities to be of the highest priority.

(5) The second meeting of the Commission was largely devoted to a scientific discussion on 'Methods of Obtaining and Measuring Radial Velocities'. The following communications were given:

Ch. Fehrenbach: Introductory Lecture.

G. de Vaucouleurs: Measurements of Radial Velocities and Velocity Dispersion in Galaxies by High-Resolution Photoelectric Spectrophotometry.

K. C. Freeman: A New Technique for Measuring Velocity Dispersions in Stellar Systems.

The meeting included a discussion on some aspects of the design of radial-velocity scanning spectrometers, with contributions by K. O. Wright and N. J. Rumsey. 